\title{
NEFROURETERECTOMIAA SIMPLIFICADA Y ONCOLÓGICAMENTE SEGURA: COMBINACIÓN CON SECCIÓN-LIGADURA URETERAL PERCUTÁNEA
}

\author{
Antoni Gelabert Mas, Héctor Hernández del Pozo y José Placer Santos.
}

Servicio y Cátedra de Urología. Hospital del Mar. Universitat Autònoma de Barcelona. Barcelona. España.

Resumen.- OBJETIVO: Proponemos una modificación de la nefroureterectomía abierta.

MÉTODO: Mediante una sola incisión (lumbotomía) se efectua una ligadura-sección percutánea del uréter terminal finamente disecado.

RESULTADOS/CONCLUSIONES: Ofrece una mejor calidad de vida en el postoperatorio inmediato, acorta el tiempo quirúrgico, y esta lumbotomía tiene la ventaja de ser oncológicamente segura, evitando una doble cirugía.
Palabras clave: Nefroureterctomía. Lumbotomía. Tumor de vías altas. Uréter terminal.

Summary.- OBJECTIVES: We propose a modification to open nephroureterectomy.

METHODS: By a single incision (lumbar incision) a percutaneous ligation-section of the finely dissected terminal ureter is performed.

RESULTS/CONCLUSIONS: This technique offers a better quality of life in the immediate postoperative period, shortens the surgical time, and it has the advantage of being oncologically safe, avoiding a double surgery.

Keywords: Nephroureterectomy. Lumbar incision. Upper urinary tract tumor. Terminal ureter.

\section{INTRODUCCIÓN}

La nefroureterectomía es el standard quirúrgico para el tratamiento local de los tumores de células transicionales infiltrantes de vía urinaria superior (5). La multicentricidad macroscópica y microscópica, demostrada por McCarron y cols. (3) de manera más frecuente en los tumores de alto grado, explica esta estrategia quirúrgica.

La nefroureterectomía clásica consiste en una sola incisión lumboadominal ampliada, tipo IsraelBergman, o bien en dos incisiones (lumbotomía y pélvica-McBurney) y actualmente la alternativa y como primera elección, la vía laparoscópica (2). En 1952 se describió una nueva estrategia que consistía en resección transuretral del meato ureteral y desinserción del uréter y posterior coagulación de la zona rese- 


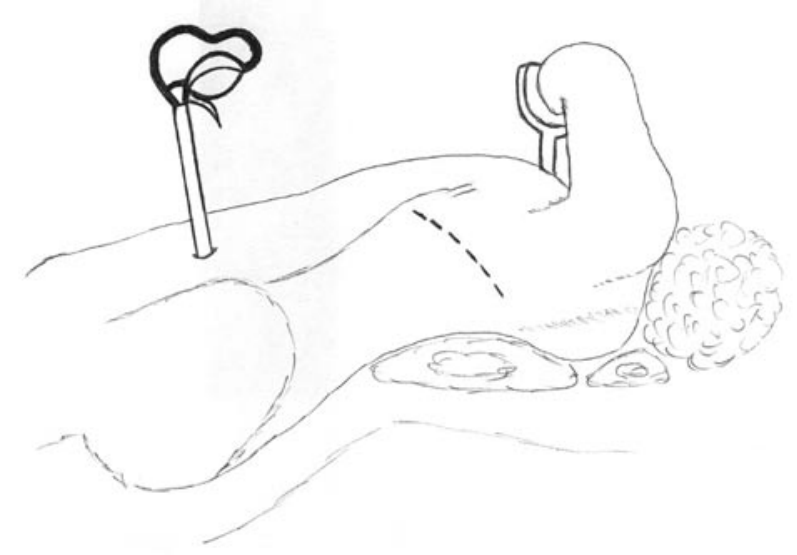

FIGURA 1. Imagen aproximada de la colocación de la pinza por incisión percutánea.

cada, lo que posibilita extraer el riñón y uréter con una sola incisión (4). Posteriormente se han descrito pequeñas modificaciones $(6,7)$.

Proponemos una modificación técnica de la nefroureterectomía por lumbotomía en una sola incisión con ligadura-sección percutánea del uréter con estanqueidad del mismo imposibilitando la diseminación tumoral; obviando los inconvenientes de la lumbotomía ampliada, de la doble incisión, y de la desinserción endoscópica del uréter distal con rodete vesical.

\section{Técnica quirúrgica}

Con el paciente en posición de lumbotomía clásica se efectua la nefrectomía por técnica estándar (disección, ligadura y sección de vasos) y aún con el riñón "in situ", sin modificar la posición del paciente y con el uréter sin manipular, se procede a la disección del mismo a torunda a través de la lumbotomía, en todo su recorrido, coagulando los pequeños vasos colaterales, hasta llegar a la inserción vesical con la vaina de Waldeyer.

Con la torunda se señala el extremo distal del uréter en su unión ureterovesical y a través de una incisión percutánea dirigida, de unos $7 \mathrm{~mm}$ a nivel pélvico, se introduce una pinza de Atlas ${ }^{\circledR}$ (Figura 1), englobando el rodete vesical al traccionar del uréter y se procede a la coagulación-sección del uréter-vejiga distal, extrayéndose en una sola pieza el riñón y uréter ocluido (Figura 2).

\section{RESULTADOS Y COMENTARIOS}

Con esta nueva táctica quirúrgica no hemos tenido ninguna complicación perioperatoria ni implantes tumorales retroperitoneales en cuatro pacientes con un año de seguimiento.

Han sido descritas diseminaciones retroperitoneales masivas con la técnica de desinserción en-

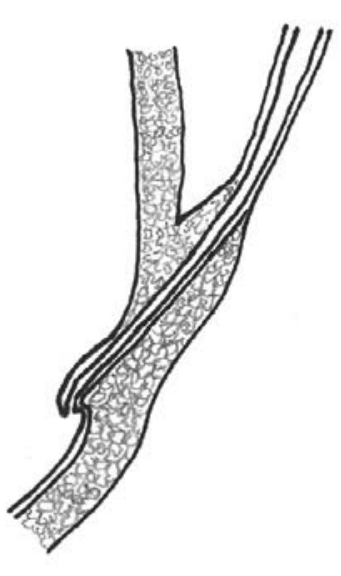

A

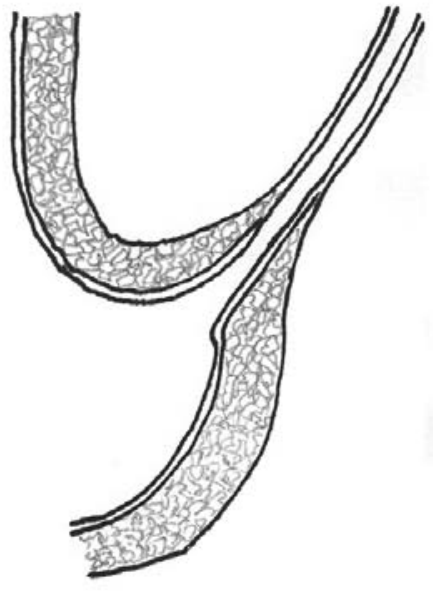

$B$
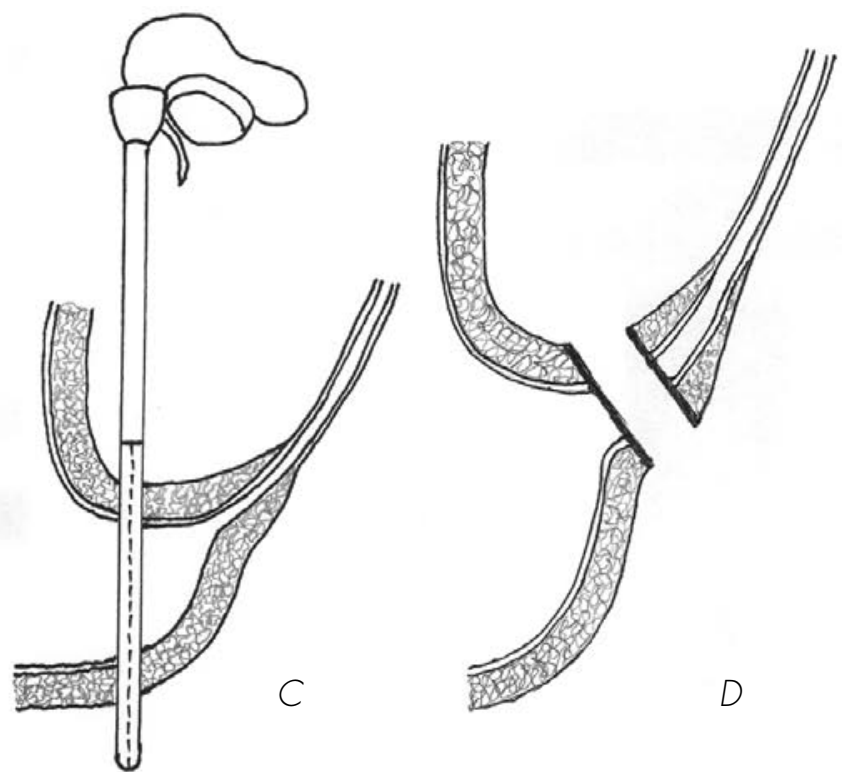

FIGURA 1. Visión esquemática de la porción intramural de la unión urétero-vesical. A, normal; B, después de la disección de la unión urétero-vesical; $C$, con la pinza colocada; $D$, después de la sección-ligadura completa de la unión urétero-vesical. 
doscópica ya que no asegura la estanqueidad del uréter distal y existe posible contaminación citológica tumoral (1).

Con esta nueva estrategia quirúrgica aseguramos la impermeabilidad de la vía excretora superior que es la responsable de la diseminación tumoral retroperitoneal al manipular endoscopicamente la desinserción transuretral. Existe un considerable beneficio de confort postoperatorio para el paciente que va sin sonda; existe un ahorro importante de tiempo quirúrgico; pero lo más importante es que aseguramos la radicalidad oncológica.

\section{BIBLIOGRAFÍA y LECTURAS RECOMENDADAS (*lectura de interés $y^{* *}$ lectura fundamental)}

**1. ARANGO, O.; BIELSA, O.; CARLES, J. y cols.: "Massive tumor implantation in the endoscopic resected area in modified nephroureterectomy". J. Urol., 157: 1839, 1997.

2. GILL, I.S.; SUNG, G.T.; HOBART, y cols.: "Laparoscopic radical nephroureterectomy for upper tract transitional cell carcinoma: The Cleveland Clinic experience". J. Urol., 164: 1513, 2000.

3. McCARRON, J.P. Jr.; CHASKO, S.B.; GRAY, G.F.Jr.: "Systematic mapping of nephroureterectomy specimens removed for urothelial cancer: Pathological findings and clinical correlations". J. Urol., 128: 243, 1982.

4. McDONALD, H.P.; UPCHURCH, W.E.; STURDEVANT, C.E.: "Nephro-ureterectomy: A new technique". J. Urol., 67: 840, 1952.

5. KIMBALL, F.N.; FERRIS, H.W.: "Papillomatous tumors of the renal pelvis associated with similar tumors of the ureter and bladder: Review of literature and report of two cases". J. Urol., 31: 257, 1934.

*6. KURAL, A.R.; DEMIRKESEN, O.; ARAR, O. y cols.: "Modified "pluck" nephroureterctomy for upper urinary tract disorders: Combined endourologic and open approach". J. Endourology, 11: 131, 1997.

**7. PALOU, J.; CAPARRÓS, J.; ORSOLA, A. y cols.: "Transurethral resection of the intramural ureter as the first step of nephroureterectomy". J. Urol., 154: 43, 1995. 